\title{
BRUCELOSE BOVINA NO ESTADO DA PARAÍBA: ESTUDO RETROSPECTIVO
}

\author{
S.M. Figueiredo ${ }^{1}$, V.C.M. Rocha ${ }^{2}$, S.S.S. Higino, \\ C.S.A. Batista ${ }^{2}$, C.J. Alves ${ }^{1}$, I.J. Clementino ${ }^{3}$, S.S. Azevedo ${ }^{1}$
}

${ }^{1}$ Universidade Federal de Campina Grande, Centro de Saúde e Tecnologia Rural, Unidade Acadêmica de Medicina Veterinária, Av. Universitária s/no, CEP 58700-970, Patos, PB, Brasil. E-mail: ssazevedo@cstr. ufcg.edu.br

\section{RESUMO}

\begin{abstract}
O objetivo do presente trabalho foi determinar a frequência de propriedades positivas (focos) e de animais soropositivos para a brucelose bovina no Estado da Paraíba. Foram utilizados dados da Agência de Defesa Agropecuária do Estado, coletados de suas 23 microrregiões, durante o período de janeiro de 2008 a julho de 2009. Durante esse período, foram examinadas 11.149 propriedades, e 55.691 soros de bovinos foram submetidos ao diagnóstico de brucelose. Para o diagnóstico sorológico, foi utilizado o teste do antígeno acidificado tamponado (AAT). Uma propriedade foi considerada foco quando apresentou pelo menos um animal soropositivo. Das propriedades investigadas, $104(0,93 \%)$ apresentaram pelo menos um animal soropositivo e, dos animais analisados, $199(0,36 \%)$ foram soropositivos. Houve diferença significativa $(\mathrm{p}<0,001)$ na proporção de fêmeas $(0,47 \%)$ e machos $(0,04 \%)$ soropositivos.
\end{abstract}

PALAVRAS-CHAVE: Brucella abortus, frequência, microrregiões, epidemiologia (controle).

\section{ABSTRACT}

BOVINE BRUCELOSIS IN THE STATE OF PARAÍBA: A RETROSPECTIVE SURVEY. The aim of this study was to determine the frequency of positive herds (foci) and seropositive animals for bovine brucellosis in the state of Paraíba, Northeast region of Brazil. Data from the Agency of Agricultural Protection in the state, collected from its 23 microregions, during the period from January 2008 to July 2009, were used. During this period, 11,149 herds were examined, and 55,691 cattle sera were submitted to the diagnosis of brucellosis. For serological diagnosis the rose bengal test was used. A herd was considered a focus when it presented at least one seropositive animal. Of the herds investigated, $104(0.93 \%)$ had at least one seropositive animal, and of the animals examined, $199(0.36 \%)$ were seropositive. There was a significant difference $(\mathrm{p}<0.001)$ in the proportion of seropositivity for females $(0.47 \%)$ and males $(0.04 \%)$.

KEY WORDS: Brucella abortus, frequency, microregions, epidemiology (control).

\section{INTRODUÇÃO}

A brucelose bovina é uma doença bacteriana de evolução crônica e caráter granulomatoso difuso, caracterizada pela infecção de células do sistema mononuclear fagocitário, causada por uma bactéria intracelular facultativa integrante do gênero Brucella, eapresentando-se em todo o mundo como problema sanitário e econômico (Paulin; FerReira Neto, 2003). Oprincipal agente etiológicoéa Brucellaabortus, cujo biotipo 1 é o mais frequente (ACHA; SZYFRES, 2001).

Na maioria dos países, a brucelose bovina ainda é um sério problema de saúde animal (MeGid et al.,
2000). Com exceção daqueles que, após programas rigorosos, conseguiram erradicá-la ou pelo menos reduzir significativamente a prevalência; nos países em desenvolvimento ainda se trata de uma questão sanitária preocupante(OMs, 1986; MATHIASet al., 2007). No Brasil, a brucelose bovina ainda é endêmica, com prevalências mais elevadas em regiões com maior densidade de bovinos (Poester et al., 2002; PAulin; FERREIRA NETO, 2003).

Com a instituição do Programa Nacional de Controle e Erradicação da Brucelose e Tuberculose Animal (PNCEBT) pelo Ministério da Agricultura, Pecuária e Abastecimento (MAPA), em 2001 (BRASIL,

${ }^{2}$ Universidade de São Paulo, Faculdade de Medicina Veterinária e Zootecnia, Departamento de Medicina Veterinária Preventiva e Saúde Animal, São Paulo, SP, Brasil.

${ }^{3}$ Serviço de Defesa Agropecuária da Paraíba, João Pessoa, PB, Brasil. 
2001), foram planejados inquéritos sorológicos como objetivo de determinar a situação epidemiológica da brucelose bovina nas Unidades Federativas e direcionar a escolha das estratégias de controle adequadas, que podem diferir de acordo com a frequência e a distribuição da doença. Até o momento, os inquéritos foram conduzidos em 15 estados, e as prevalências de animais soropositivos variaram de 0,06\%, em Santa Catarina, a 10,2\%, em Mato Grosso (Alves et al., 2009; AzEVEDo et al., 2009; CHATE et al., 2009; DiAs et al., 2009a; DiAs et al., 2009b; GONÇALVES et al., 2009a; GonÇALVES et al., 2009b; KLEIN-GUNNEWIEK et al., 2009; Marvulo et al., 2009; Negreiros et al., 2009; OGATA et al., 2009; Rocha et al., 2009; SIKUSAWA et al., 2009; SILVA et al., 2009; VILLAR et al., 2009). Contudo, no Estado da Paraíba o inquérito ainda não foi iniciado.

Dessa maneira, o presente trabalho foi estruturado com o objetivo de determinar a frequência de propriedades positivas e de animais soropositivos para a brucelose bovina no Estado da Paraíba, utilizando dados do Serviço de Defesa Agropecuária do Estado relativos aos relatórios emitidos por médicos veterinários habilitados pelo MAPA para diagnóstico da brucelose bovina, no período de janeiro de 2008 a julho de 2009.

\section{MATERIAL E MÉTODOS}

\section{Caracterização do Estado}

O Estado da Paraíba possui uma população de 3.641.395 habitantes, distribuída em 223 municípios e 23 microrregiões geográficas, a saber: Brejo Paraibano, Cajazeiras, Campina Grande, Cariri Ocidental, Cariri Oriental, Catolé do Rocha, Curimataú Ocidental, Curimataú Oriental, Esperança, Guarabira, Itabaiana, Itaporanga, João Pessoa, Litoral Norte, Litoral Sul, Patos, Piancó, Sapé, Seridó Ocidental Paraibano, Seridó Oriental Paraibano, Serra do Teixeira, Sousa, Umbuzeiro. O Estado conta com um efetivo de 92.024 mil estabelecimentos pecuários criadores de bovinos, com efetivo de 1.313.662 animais (IBGE, 2006).

\section{Levantamento de dados e diagnóstico sorológico}

O Serviço de Defesa Agropecuária da Paraíba possui 27 Unidades Locais de Sanidade Animal e Vegetal (ULSAV), cinco gerências regionais e uma unidade central. No presente trabalho, foram utilizados os condensados estaduais dos informes mensais sobre a ocorrência e o diagnóstico de brucelose e do informe de vacinação contra brucelose que são obtidos após análise dos relatórios mensais emitidos por médicos veterinários das diferentes microrregiões do Estado, habilitados pelo MAPA para diagnóstico da brucelose bovina e cadastrados no Serviço de Defesa Agropecuária da Paraíba para execução das atividades de vacinação contra brucelose. O período do estudo foi de janeiro de 2008 a julho de 2009. Os dados de vacinação compreenderam o período de janeiro a dezembro de 2008.

Para o diagnóstico sorológico da infecção por Brucella abortus foi utilizado o teste do antígeno acidificado tamponado (AAT) (BRASIL, 2006), realizado nas salas de diagnóstico dos médicos veterinários habilitados no PNCEBT na Paraíba. Apenas uma pequena parte dos animais reagentes positivos ao AAT foi submetida ao teste confirmatório de fixação de complemento, por solicitação dos produtores, de maneira que, no presente trabalho, o resultado do teste do AAT foi considerado definitivo.

\section{Análise dos dados}

Uma propriedade foi considerada positiva (foco) quando apresentou pelo menos um animal soropositivo. Foram calculadas as frequências de focos por microrregião, bem como a frequência de animais soropositivos por microrregião e por sexo. Para a confecção dos mapas georreferenciados, foi utilizado o programa ArcGIS versão 9.2. Para a comparação das proporções de fêmeas e machos soropositivos, foi utilizado o teste de qui-quadrado (ZAR, 1999), com nível de significância de $5 \%$, utilizando o programa EpiInfo 6.04 (DEAN, 1994).

\section{RESULTADOS}

No total, foram examinadas 11.149 propriedades, no período de janeiro de 2008 a julho de 2009. Das propriedades investigadas, $104(0,93 \%)$ apresentaram pelo menos um animal soropositivo (Tabela 1). Em relação aos animais, 55.691 bovinos foram submetidos ao diagnóstico de brucelose, dos quais $199(0,36 \%)$ foram soropositivos.

Das 41.615 fêmeas, $194(0,47 \%)$ foram soropositivas, e dos 14.076 machos, cinco $(0,04 \%)$ foram soropositivos (Tabela 2), havendo uma diferença significativa na frequência de soropositividade entre fêmeas e machos ( $p<0,001)$. Nas Figuras 1 e 2 é apresentada a distribuição de focos e de animais soropositivos por microrregião do Estado da Paraíba, no período de janeiro de 2008 a julho de 2009.

No ano de 2008, dos 54.135 rebanhos cadastrados no serviço oficial do Estado, em 2.184 (4,03\%) era praticada a vacinação contra brucelose bovina com a vacina B19. Já para os animais, das 69.629 bezerras com idade até 12 meses, 11.806 (16,96\%) foram vacinadas entre três e oito meses de idade (Tabela 3). 
Tabela 1 - Focos de brucelose bovina distribuídos nas 23 microrregiões do Estado da Paraíba, no período de janeiro de 2008 a julho de 2009.

\begin{tabular}{|c|c|c|c|}
\hline \multirow{3}{*}{ Microrregião } & \multicolumn{3}{|c|}{ Diagnóstico sorológico } \\
\hline & \multicolumn{3}{|c|}{ Rebanhos } \\
\hline & Propriedades examinadas & Propriedades positivas & $\%$ \\
\hline Brejo Paraibano & 292 & 5 & 1,71 \\
\hline Cajazeiras & 378 & 1 & 0,26 \\
\hline Campina Grande & 674 & 7 & 1,04 \\
\hline Cariri Ocidental & 743 & 3 & 0,40 \\
\hline Cariri Oriental & 373 & 2 & 0,54 \\
\hline Catolé do Rocha & 641 & 15 & 2,34 \\
\hline Curimataú Ocidental & 711 & 6 & 0,84 \\
\hline Curimataú Oriental & 185 & 7 & 3,78 \\
\hline Esperança & 424 & 1 & 0,24 \\
\hline Guarabira & 534 & 7 & 1,31 \\
\hline Itabaina & 493 & 1 & 0,20 \\
\hline Itaporanga & 594 & 2 & 0,34 \\
\hline João Pessoa & 88 & 2 & 2,27 \\
\hline Litoral Norte & 243 & 0 & 0,00 \\
\hline Litoral Sul & 8 & 0 & 0,00 \\
\hline Patos & 421 & 3 & 0,71 \\
\hline Piancó & 492 & 7 & 1,42 \\
\hline Sapé & 219 & 5 & 2,28 \\
\hline Seridó Ocidental Paraibano & 333 & 1 & 0,30 \\
\hline Seridó Oriental Paraibano & 818 & 0 & 0,00 \\
\hline Serra do Teixeira & 1.057 & 5 & 0,47 \\
\hline Sousa & 1.261 & 24 & 1,90 \\
\hline Umbuzeiro & 167 & 0 & 0,00 \\
\hline Total & 11.149 & 104 & 0,93 \\
\hline
\end{tabular}

Tabela 2 - Animais soropositivos para brucelose bovina, nas 23 microrregiões do Estado da Paraíba, no ano período de janeiro de 2008 a julho de 2009.

\begin{tabular}{|c|c|c|c|c|c|c|c|c|c|c|}
\hline \multirow{3}{*}{ Microrregião } & \multicolumn{10}{|c|}{ Diagnóstico sorológico } \\
\hline & \multicolumn{2}{|c|}{ Animais examinados } & \multicolumn{4}{|c|}{ Animais positivos } & \multicolumn{4}{|c|}{ Animais inconclusivos } \\
\hline & Fêmea & Macho & Fêmea & $\%$ & Macho & $\%$ & Fêmea & $\%$ & Macho & $\%$ \\
\hline Brejo Paraibano & 1.124 & 553 & 8 & 0,71 & 0 & 0,00 & 0 & 0,00 & 0 & 0,00 \\
\hline Cajazeiras & 2.664 & 105 & 1 & 0,04 & 0 & 0,00 & 0 & 0,00 & 0 & 0,00 \\
\hline Campina Grande & 3.853 & 753 & 8 & 0,21 & 2 & 0,27 & 0 & 0,00 & 0 & 0,00 \\
\hline Cariri Ocidental & 1.327 & 2.161 & 2 & 0,15 & 0 & 0,00 & 0 & 0,00 & 0 & 0,00 \\
\hline Cariri Oriental & 1.043 & 707 & 2 & 0,19 & 0 & 0,00 & 0 & 0,00 & 0 & 0,00 \\
\hline Catolé do Rocha & 2.136 & 300 & 18 & 0,84 & 0 & 0,00 & 0 & 0,00 & 0 & 0,00 \\
\hline Curimataú Ocidental & 1.624 & 1.050 & 6 & 0,37 & 1 & 0,10 & 0 & 0,00 & 0 & 0,00 \\
\hline Curimataú Oriental & 1.986 & 756 & 76 & 3,83 & 0 & 0,00 & 1 & 0,05 & 0 & 0,00 \\
\hline Esperança & 653 & 395 & 1 & 0,15 & 0 & 0,00 & 0 & 0,00 & 0 & 0,00 \\
\hline Guarabira & 2.631 & 786 & 14 & 0,53 & 0 & 0,00 & 0 & 0,00 & 0 & 0,00 \\
\hline Itabaina & 1.966 & 1.054 & 1 & 0,05 & 0 & 0,00 & 0 & 0,00 & 0 & 0,00 \\
\hline Itaporanga & 2.213 & 73 & 2 & 0,09 & 0 & 0,00 & 0 & 0,00 & 0 & 0,00 \\
\hline João Pessoa & 697 & 11 & 7 & 1,00 & 0 & 0,00 & 2 & 0,29 & 0 & 0,00 \\
\hline Litoral Norte & 1.516 & 534 & 0 & 0,00 & 0 & 0,00 & 0 & 0,00 & 0 & 0,00 \\
\hline Litoral Sul & 43 & 0 & 0 & 0,00 & 0 & 0,00 & 0 & 0,00 & 0 & 0,00 \\
\hline Patos & 1.635 & 480 & 4 & 0,24 & 0 & 0,00 & 0 & 0,00 & 0 & 0,00 \\
\hline Piancó & 2.377 & 256 & 7 & 0,29 & 0 & 0,00 & 0 & 0,00 & 0 & 0,00 \\
\hline Sapé & 1.283 & 741 & 6 & 0,47 & 0 & 0,00 & 0 & 0,00 & 0 & 0,00 \\
\hline Seridó Ocidental Paraibano & 655 & 345 & 0 & 0,00 & 0 & 0,00 & 0 & 0,00 & 0 & 0,00 \\
\hline Seridó Oriental Paraibano & 1.236 & 1.061 & 0 & 0,00 & 0 & 0,00 & 0 & 0,00 & 0 & 0,00 \\
\hline
\end{tabular}

Continua 
Tabela 2 - Continuação

\begin{tabular}{|c|c|c|c|c|c|c|c|c|c|c|}
\hline \multirow{3}{*}{ Microrregião } & \multicolumn{10}{|c|}{ Diagnóstico sorológico } \\
\hline & \multicolumn{2}{|c|}{ Animais examinados } & \multicolumn{4}{|c|}{ Animais positivos } & \multicolumn{4}{|c|}{ Animais inconclusivos } \\
\hline & Fêmea & Macho & Fêmea & $\%$ & Macho & $\%$ & Fêmea & $\%$ & Macho & $\%$ \\
\hline Serra do Teixeira & 1.493 & 1.228 & 3 & 0,20 & 2 & 0,16 & 0 & 0,00 & 0 & 0,00 \\
\hline Sousa & 6.882 & 239 & 28 & 0,41 & 0 & 0,00 & 0 & 0,00 & 0 & 0,00 \\
\hline Umbuzeiro & 578 & 488 & 0 & 0,00 & 0 & 0,00 & 0 & 0,00 & 0 & 0,00 \\
\hline Total & 41.615 & 14.076 & 194 & 0,47 & 5 & 0,04 & 3 & 0,01 & 0 & 0,00 \\
\hline
\end{tabular}

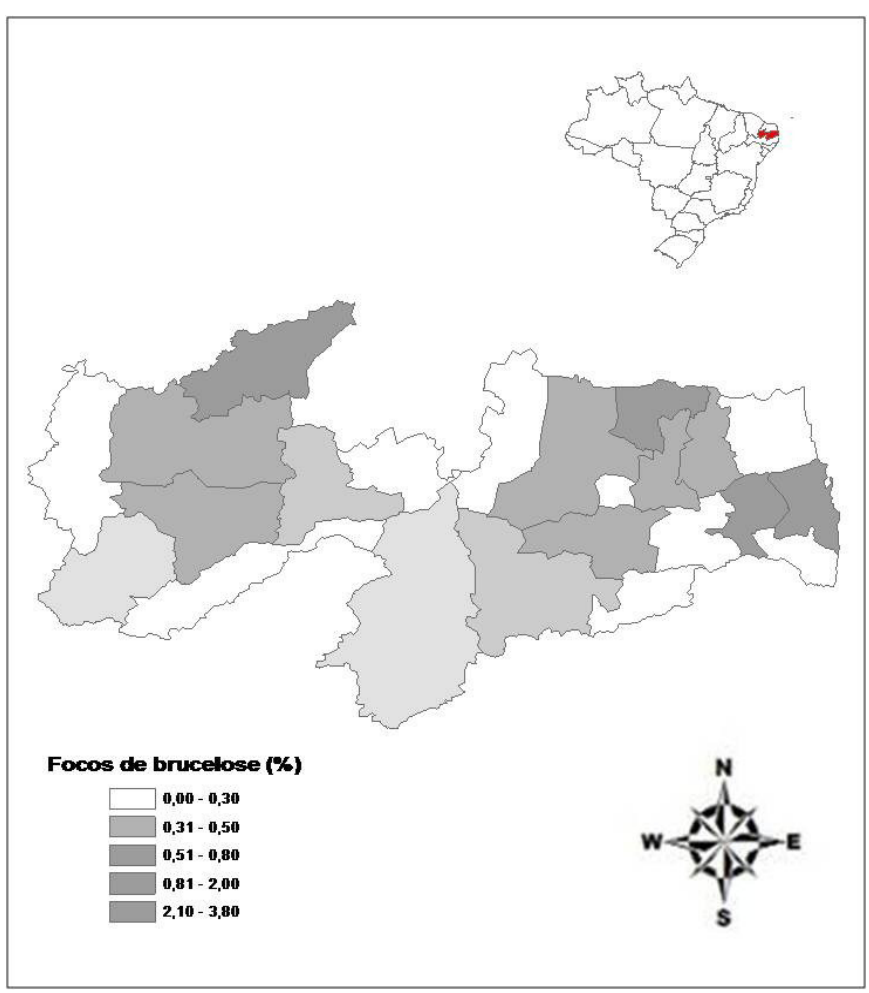

Fig. 1 - Frequência de focos de brucelose (propriedades positivas), nas 23 microrregiões do Estado da Paraíba, no período de janeiro de 2008 a julho de 2009.

Fig. 2 - Frequência de animais soropositivos para a brucelose bovina nas 23 microrregiões do Estado da Paraíba, no período de janeiro de 2008 a julho de 2009.

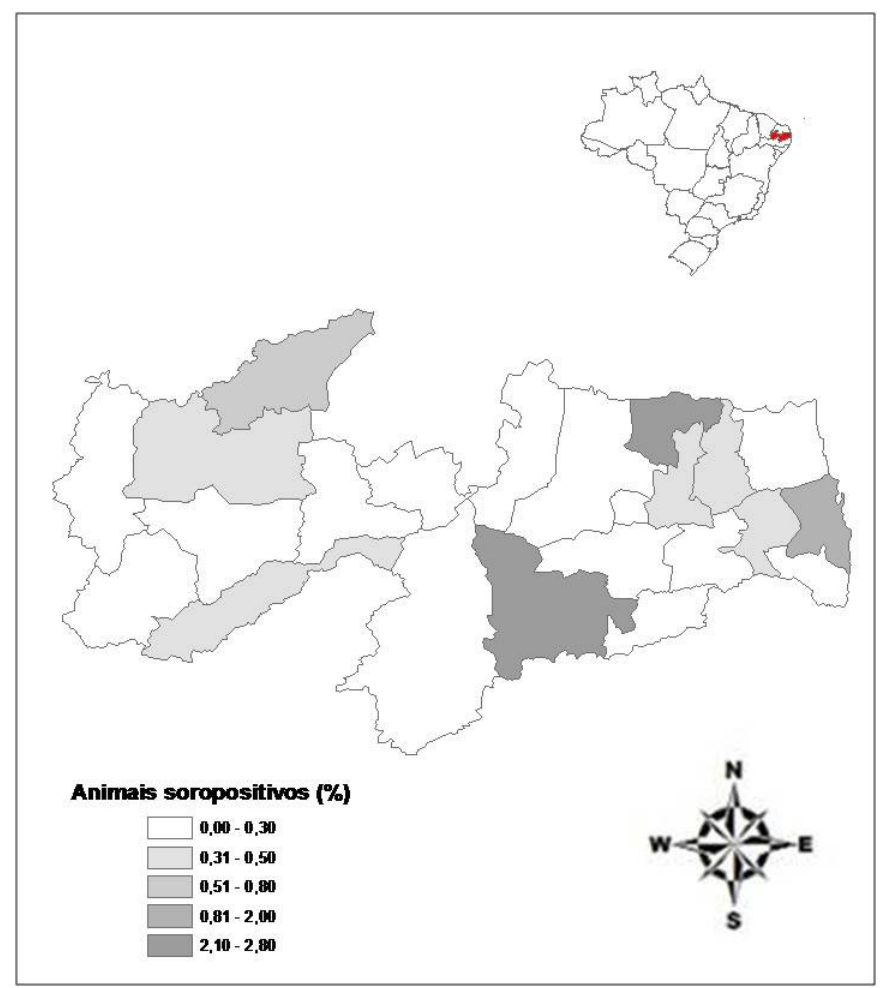


Tabela 3 - Vacinação das fêmeas em idade reprodutiva no Estado da Paraíba, no período de janeiro a dezembro de 2008.

\begin{tabular}{|c|c|c|c|c|c|c|}
\hline \multirow[b]{2}{*}{ Microrregião } & \multicolumn{3}{|c|}{ Número de rebanhos } & \multicolumn{3}{|c|}{ Número de bezerras } \\
\hline & $\begin{array}{c}\text { Existentes } \\
\text { (cadastrados) }\end{array}$ & Vacinados & $\%$ & $\begin{array}{c}\text { Existentes } \\
\text { (até } 12 \text { meses) }\end{array}$ & $\begin{array}{l}\text { Vacinadas } \\
3 \text { - } 8 \text { meses }\end{array}$ & $\%$ \\
\hline Brejo Paraibano & 1.304 & 46 & 3,53 & 1.360 & 830 & 61,03 \\
\hline Cajazeiras & 3.608 & 122 & 3,38 & 4.614 & 984 & 21,33 \\
\hline Campina Grande & 1.490 & 73 & 4,90 & 1.235 & 501 & 40,57 \\
\hline Cariri Ocidental & 5.879 & 172 & 2,93 & 5.509 & 657 & 11,93 \\
\hline Cariri Oriental & 2.225 & 112 & 5,03 & 3.004 & 564 & 18,77 \\
\hline Catolé do Rocha & 2.195 & 121 & 5,51 & 2.960 & 984 & 33,24 \\
\hline Curimataú Ocidental & 2.472 & 163 & 6,59 & 2.675 & 496 & 18,54 \\
\hline Curimataú Oriental & 2.432 & 81 & 3,33 & 2.903 & 459 & 15,81 \\
\hline Esperança & 681 & 6 & 0,88 & 427 & 19 & 4,45 \\
\hline Guarabira & 2.126 & 86 & 4,05 & 3.092 & 1.044 & 33,76 \\
\hline Itabaiana & 2.293 & 111 & 4,84 & 4.127 & 872 & 21,13 \\
\hline Itaporanga & 3.246 & 0 & 0,00 & 3.827 & 0 & 0,00 \\
\hline João Pessoa & 975 & 2 & 0,21 & 879 & 62 & 7,05 \\
\hline Litoral Norte & 3.264 & 75 & 2,30 & 4.228 & 605 & 14,31 \\
\hline Litoral Sul & 179 & 2 & 1,12 & 343 & 16 & 4,66 \\
\hline Patos & 2.249 & 121 & 5,38 & 4.639 & 736 & 15,87 \\
\hline Piancó & 2.655 & 26 & 0,98 & 4.508 & 123 & 2,73 \\
\hline Sapé & 2.448 & 45 & 1,84 & 2.223 & 349 & 15,70 \\
\hline Seridó Ocidental Paraibano & 751 & 119 & 15,85 & 1.414 & 414 & 29,28 \\
\hline Seridó Oriental Paraibano & 3.548 & 59 & 1,66 & 3.180 & 147 & 4,62 \\
\hline Serra do Teixeira & 3.344 & 531 & 15,88 & 3.794 & 1.238 & 32,63 \\
\hline Sousa & 4.022 & 104 & 2,59 & 6.763 & 681 & 10,07 \\
\hline Umbuzeiro & 749 & 7 & 0,93 & 1.925 & 25 & 1,30 \\
\hline Total & 54.135 & 2.184 & 4,03 & 69.629 & 11.806 & 16,96 \\
\hline
\end{tabular}

\section{DISCUSSÃO}

Os dados de notificações oficiais, publicados em Boletins da DefesaSanitária Animal, indicaram quea prevalência de animais soropositivos para brucelose, no Brasil, manteve-se entre $4,0 \%$ e $5,0 \%$, no período de 1988 a 1998 (Ferreira Neto, 2009). No Estado da Paraíba, o último levantamento de animais soropositivos para brucelose bovina, realizado em 1975, indicou que a frequência de animais soropositivos no Estado foi 0,80\% (Paulin; Ferreira Neto, 2003). No presente trabalho, foi constatada que a frequência de bovinos soropositivos $(0,36 \%)$ manteve-se num grau de estabilidade com tendência ao declínio. Isso demonstra que o Estado tem, historicamente, baixa prevalência de brucelose, provavelmente em virtude da boa estruturação dos serviços oficiais aliada às características produtivas do Estado, constituído por pequenas propriedades com poucos animais, em comparação a outros estados brasileiros. Por outro lado, vale ressaltar que uma possível subnotificação, ao serviço de defesa sanitária animal, dos resultados positivos nos testes de diagnóstico de brucelose, possa ter contribuído para essa baixa frequência.

As maiores frequências de propriedades e de animais soropositivos, no período em estudo (janeiro de 2008 a julho de 2009), nas 23 microrregiões, foram observadas na microrregião do Curimataú Oriental.
Segundo informação do Serviço de Defesa Sanitária do Estado (CLEMENTINO, comunicação pessoal), na microrregião do Curimataú Oriental, os proprietários relataram que adquiriram os animais em anos anteriores vindos dos estados de MG, AL e PE sem exigência de testes de brucelose. De acordo com CRAWFORD et al. (1990), a compra de animais é considerada o principal fator de risco para a introdução da brucelose em rebanhos livres, e a intensidade do risco pode variar de acordo com a fonte da compra.a

$\mathrm{O}$ combate à brucelose bovina pode ser dividido em quatro fases distintas (PAULIN; FerReIRA NETO, 2003): (a) rebaixamento da prevalência para valores inferiores a $2 \%$, sendo necessária para isso uma cobertura vacinal de $80 \%$ com a vacina B19; (b) abandono da vacinação e adoção das medidas de diagnóstico e sacrifício sistemáticos dos animais soropositivos; (c) solução de problemas residuais; e (d) adoção de ações de vigilância para que o retorno da infecção seja impedido, ou caso reapareça, seja rapidamente detectado e eliminado. Com base no estudo epidemiológico realizado no Estado de Santa Catarina, no qual a prevalência de focos foi de $0,32 \%$ e a prevalência de animais soropositivos foi de 0,06\% (SIKUSAWA et al., 2009), o MAPA publicou uma portaria em 2004 excluindo a obrigatoriedade de vacinação contra a brucelose bovina nesse Estado (BRASIL, 2004). 
No presente trabalho, apesar de as frequências de focos e animais soropositivos terem sido baixas $(0,93 \%$ e $0,36 \%$,respectivamente) edo númeroconsiderável de propriedades $(n=11.149)$ e de animais $(n=$ 55.691), não foi realizado um planejamento amostral para o Estado, bem como não foram estabelecidos critérios de seleção de propriedades e animais, o que pode influenciar na determinação das frequências de focos e animais soropositivos, de modo que se torna incoerente sugerir alguma estratégia de ação. Dequalquer maneira, a despeito da baixa frequência de focos e de animais soropositivos, e considerando as condições econômicas da produção de bovinos do Estado, sugere-se que esforços sejam concentrados na intensificação da vacinação de bezerras, com o intuito de que seja alcançada uma prevalência compatível com as ações de teste e sacrifício de animais. Some-se a isso o fato de que a cobertura vacinal no Estado, 16,96\% (Tabela 3), ainda é baixa.

No presente trabalho, as fêmeas bovinas apresentaram uma maior soropositividade $(0,47 \%)$ para brucelose comparada àquela observada para machos $(0,04 \%)(p<0,001)$. Tal fato já era esperado, uma vez que fêmeas bovinas são mais susceptíveis que os machos, especialmentequando prenhes, por propiciarum meio adequado à multiplicação das brucelas em seu aparelho reprodutivo, equase todas as fêmeas infectadas permanecem cronicamente nessa condição, com o agente presente no útero e em linfonodos (OMS, 1986).

\section{CONCLUSÕES}

Com base nos resultados obtidos no presente trabalho, conclui-se que as frequências de propriedades positivas (focos) $(0,93 \%)$ e de animais soropositivos $(0,36 \%)$ para brucelose bovina no Estado da Paraíba, no período de janeiro de 2008 a julho de 2009, foram baixas. No entanto, considerando as condições econômicas da produção de bovinos do Estado, bem como a ausência de planejamento amostral adequado, sugere-se que esforços sejam concentrados na intensificação da vacinação de bezerras, com o intuito de que seja alcançada uma prevalência compatível com as ações de teste e sacrifício de animais. Houve uma maior frequência de fêmeas bovinas soropositivas em comparação com machos, confirmando a maior susceptibilidade de fêmeas à infecção por Brucella abortus.

\section{AGRADECIMENTOS}

À Defesa Agropecuária do Estado da Paraíba - Secretaria de Estado do Desenvolvimento da Agropecuária e da Pesca (SEDAP) pela concessão dos dados.

\section{REFERÊNCIAS}

ACHA, P.N.; SZYFRES, B. Zoonosis y enfermedades transmisibles comunes al hombre y a los animales: Bacteriosis y micosis. 3.ed. Washington: OPAS, 2001. 416p.

ALVES, A.J.S.; GONÇALVES, V.S.P.; FIGUEIREDO, V.C.F.; LÔBO, J.R.; BAHIENSE, L.; AMAKU, M.; FERREIRA, F.; FERREIRA NETO, J.S.; DIAS, R.A. Situação epidemiológica da brucelose bovina no Estado da Bahia. Arquivo Brasileiro de Medicina Veterinária e Zootecnia, v.61, p. 6-13, 2009. Suplemento 1.

AZEVEDO, S.S.; FERREIRA NETO, J.S.; DIAS, R.A.; FERREIRA, F.; AMAKU, M.; FIGUEIREDO, V.C.F.; LÔBO, J.R.; GONÇALVES, V.S.P.; SOUZA, A.C.; VASCONCELLOS, S.A. Situação epidemiológica da brucelose bovina no Estado do Espírito Santo. Arquivo Brasileiro de Medicina Veterinária e Zootecnia, v.61, p.1926, 2009. Suplemento 1.

BRASIL. Ministério da Agricultura, Pecuária e Abastecimento. Programa Nacional de Controle e Erradicação da Brucelose e da Tuberculose Animal. Brasília, DF: PNCEBT, 2006. 188p. (Manual Técnico).

BRASIL. Ministério da Agricultura, Pecuária e Abastecinto de Defesa Animal. Instrução Normativa No.2, de 10 de janeiro de 2001. Programa Nacional de Controle e Erradicação da Brucelose e Tuberculose Animal. Diário Oficial da República Federativa do Brasil, Poder Executivo, Brasília, DF, 16 de janeiro de 2001, Seção 1, p.11-17.

BRASIL. Ministério da Agricultura, Pecuária e Abastecimento (MAPA). Secretaria de Defesa Agropecuária. Departamento de Defesa Animal. Portaria n.11, de 26 de janeiro de 2004. Excluir o Estado de Santa Catarina da obrigatoriedade de vacinação das fêmeas bovinas e bubalinas contra a brucelose. Diário Oficial da União, Brasília, 29 de janeiro de 2004, Seção 1, p.3.

CHATE, S.C.; DIAS, R.A.; AMAKU, M.; FERREIRA, F.; MORAES, G.M.; COSTA NETO, A.A.; MONTEIRO, L.A.R.C.; LÔBO, J.R.; FIGUEIREDO, V.C.F.; GONÇALVES, V.S.P.; FERREIRA NETO, J.S. Situação epidemiológica da brucelose bovina no Estado do Mato Grosso do Sul. Arquivo Brasileiro de Medicina Veterinária e Zootecnia, v.61, p. 46-55, 2009. Suplemento 1.

CRAWFORD, R.P.; HUBER, J.D.; ADAMS, B.S. EPIDEMIOLOGY AND SURVEILLANCE. IN: NIELSEN, K.; DUNCAN, J.R. Animal brucellosis. Boca Raton: CRC Press, 1990. p.131-151.

DEAN, A.G.; DEAN, J.A.; COLOMBIER, D. Epi-Info, version 6: A word processing database and statistics program for epidemiology on microcomputers. Atlanta: CDC, 1994. 601p.

DIAS, J.A.; MÜLLER, E.E.; DIAS, R.A.; FREITAS, J.C.; AMAKU, M.; FERREIRA, F.; SILVA, M.C.P.; LÔBO, 
J.R.; FIGUEIREDO, V.C.F.; GONÇALVES, V.S.P.; FERREIRA NETO, J.S. Situação epidemiológica da brucelose bovina no Estado do Paraná. Arquivo Brasileiro de Medicina Veterinária e Zootecnia, v.61, p.66-76, 2009a. Suplemento 1.

DIAS, R.A.; GONÇALVES, V.S.P.; FIGUEIREDO, V.C.F.; LÔBO, J.R.; LIMA, Z.M.B.; PAULIN, L.M.S.; GUNNEWIEK, M.F.K.; AMAKU, M.; FERREIRA NETO, J.S.; FERREIRA, F. Situação epidemiológica da brucelose bovina no Estado de São Paulo. Arquivo Brasileiro de Medicina Veterinária e Zootecnia, v.61, p.118-125, 2009b. Suplemento 1.

FERREIRA NETO, J. S. Situação epidemiológica da brucelose bovina no Brasil: bases para as intervenções. 2009. Disponível em: <http://www.revistas.ufg.br/ index.php/vet/article/viewFile/7669/5442> Acesso em: 13 jan. 2009.

GONÇALVES, V.S.P.; RIBEIRO, L.A.; CALDAS, R.A.; FRANCISCO, P.F.C.; DIAS, R.A.; FERREIRA, F.; AMAKU, M.; FERREIRA NETO, J.S.; FIGUEIREDO, V.C.F.; LÔBO, J.R.; BORGES, J.R.J. Situação epidemiológica da brucelose bovina no Distrito Federal. Arquivo Brasileiro de Medicina Veterinária e Zootecnia, v.61, p.1418, 2009a. Suplemento 1.

GONÇALVES, V.S.P.; DELPHINO, M.K.V.C.; DIAS, R.A.; FERREIRA, F.; AMAKU, M.; FERREIRA NETO, J.S.; PORTO, T.B.; ALVES, C.M.; FIGUEIREDO, V.C.F.; LÔBO, J.R. Situação epidemiológica da brucelose bovina no Estado de Minas Gerais. Arquivo Brasileiro de Medicina Veterinária e Zootecnia, v.61, p.35-45, 2009b. Suplemento 1.

IBGE - INSTITUTO BRASILEIRO DE GEOGRAFIA E ESTATíSTICA. Censo Agropecuário de 2006. 2006. Disponível em: <http://www.ibge.com.br/estadosat/temas. php?sigla $=$ pb\&tema $=$ censoagro $>$. Acesso em 10 out. 2009.

KLEIN-GUNNEWIEK, M.F.C.; AMAKU, M.; DIAS, R.A.; FERREIRA, F.; GITTI, C.B.; PEREIRA, L.A.; FIGUEIREDO, V.C.F.; LOBO, J.R.; GONÇALVES, V.S.P.; FERREIRA NETO, J.S. Situação epidemiológica da brucelose bovina no Estado do Rio de Janeiro. Arquivo Brasileiro de Medicina Veterinária e Zootecnia, v.61, p.77-84, 2009. Suplemento 1.

MARVULO, M.F.V.; FERREIRA, F.; DIAS, R.A.; AMAKU, M.; GROFF, A.C.M.; GONÇALVES, V.S.P.; FIGUEIREDO, V.C.F.; LÔBO, J.R.; FERREIRA NETO, J.S. Situação epidemiológica da brucelose bovina no Estado do Rio Grande do Sul. Arquivo Brasileiro de Medicina Veterinária e Zootecnia, v.61, p. 93-102, 2009. Suplemento 1.

MATHIAS, L. A.; MEIRELLES, R. B.; BUCHALA, F. G. Estabilidade do antígeno de célula total de Brucella abortus para uso no diagnóstico sorológico da brucelose bovina pela reação de fixação de complemento. Pesquisa Veterinária Brasileira, v.27, n.1, p.18-22, 2007.
MEGID, J.; RIBEIRO, M. G.; MARCOS JUNIOR, G.; CROCCI, A. J. Avaliação das provas de soroaglutinação rápida, soroaglutinação lenta, antígeno acidificado e 2-mercaptoetanol no diagnóstico da brucelose bovina. Brazilian Journal of Veterinary Research and Animal Science, v.37, n.5, 2000. doi: 10.1590/S141395962000000500009

NEGREIROS, R.L.; DIAS, R.A.; FERREIRA, F.; FERREIRA NETO, J.S.; GONÇALVES, V.S.P.; SILVA, M.C.P.; FIGUEIREDO, V.C.F.; LÔBO, J.R.; FREITAS, J.; AMAKU, M. Situação epidemiológica da brucelose bovina no Estado de Mato Grosso. Arquivo Brasileiro de Medicina Veterinária e Zootecnia, v.61, p. 56-65, 2009. Suplemento 1.

OGATA, R.A.; GONÇALVES, V.S.P.; FIGUEIREDO, V.C.F.; LÔBO, J.R.; RODRIGUES, A.L.; AMAKU, M.; FERREIRA, F.; FERREIRA NETO, J.S.; DIAS, R.A. Situação epidemiológica da brucelose bovina no Estado do Tocantins. Arquivo Brasileiro de Medicina Veterinária e Zootecnia, v.61, supl. 1, p.126-134, 2009. Suplemento 1.

ORGANIZACIÓN MUNDIAL DE LA SALUD. Comité Mixto FAO/OMS de Expertos en Brucelosis. Ginebra : Organización Mundial de la Salud, 1986. p 149. (Serie de Informes Técnicos, 740).

PAULIN, L.M.; FERREIRA NETO J.S. O combate à brucelose bovina: situação brasileira, Jaboticabal: FUNEP, 2003, 154p.

POESTER, F.P.; GONÇALVES, V.S.P.; LAGE, A.P. Brucellosis in Brazil. Veterinary Microbiology, v. 90, p. 55-62, 2002.

ROCHA, W.V.; GONÇALVES, V.S.P.; COELHO, C.G.N.F.L.; BRITO, W.M.E.D.; DIAS, R.A.; DELPHINO, M.K.V.C.; FERREIRA, F.; AMAKU, M.; FERREIRA NETO, J.S.; FIGUEIREDO, V.C.F.; LÔBO, J.R.; BRITO, L.A.B. Situação epidemiológica da brucelose bovina no Estado de Goiás. Arquivo Brasileiro de Medicina Veterinária e Zootecnia, v.61, p.27-34, 2009. Suplemento 1.

SIKUSAWA, S.; AMAKU, M.; DIAS, R. A.; FERREIRA NETO, J. S.; MARTINS, C.; GONÇALVES, V. S. P.; FIGUEIREDO, V. C. F.; LÔBO, J. R.; FERREIRA, F. Situação epidemiológica da brucelose bovina no Estado de Santa Catarina. Arquivo Brasileiro de Medicina Veterinária e Zootecnia, v.61, p.103-108, 2009. Suplemento 1.

SILVA, V.G.S.O.; DIAS, R.A.; FERREIRA, F.; AMAKU, M.; COSTA, E.L.S.; LÔBO, J.R.; FIGUEIREDO, V.C.F.; GONÇALVES, V.S.P.; FERREIRA NETO, J.S. Situação epidemiológica da brucelose bovina no Estado de Sergipe. Arquivo Brasileiro de Medicina Veterinária e Zootecnia, v.61, p.109-117, 2009. Suplemento 1.

VILLAR, K.S.; AMAKU, M.; DIAS, R.A.; FERREIRA NETO, J.S.; BENITEZ, F.; GONÇALVES, V.S.P.; FI- 
GUEIREDO, V.C.F.; LÔBO, J.R.; FERREIRA, F. Situação epidemiológica da brucelose bovina no Estado de Rondônia. Arquivo Brasileiro de Medicina Veterinária e Zootecnia, v.61, p.85-92, 2009. Suplemento 1 .
ZAR, J.H. Biostatistical analysis. 4.ed. Upper Saddle River: Prentice Hall, 1999. 663p.

Recebido em 3/2/10

Aceito em 4/1/11 